\title{
A Stability Indicating Assay Method Development and Validation for the Frovatriptan Succinate Monohydrate by Using UV: A Spectrophotometric Technique
}

\author{
Hitesh Verma, Surajpal Verma, and Harmanpreet Singh \\ School of Pharmaceutical Sciences, Lovely Faculty of Applied Medical Sciences, Lovely Professional University, \\ Phagwara, Punjab 144411, India
}

Correspondence should be addressed to Hitesh Verma; verma2908@gmail.com

Received 6 March 2013; Accepted 10 April 2013

Academic Editors: W. A. Badawy, I. P. Gerothanassis, and X. Shi

Copyright (C) 2013 Hitesh Verma et al. This is an open access article distributed under the Creative Commons Attribution License, which permits unrestricted use, distribution, and reproduction in any medium, provided the original work is properly cited.

\begin{abstract}
A new simple, reliable, inexpensive, and accurate method was developed for the quantification of Frovatriptan Succinate Monohydrate in different physiological media at $244 \mathrm{~nm}$ in bulk and in tablet dosage forms. The developed method is an attempt to surpass the disadvantages associated with the reported methods, namely, less sensitive and tedious in usage for routine purposes. Beer's law was followed over the range of $1.0 \mu \mathrm{g} / \mathrm{mL}$ to $4.5 \mu \mathrm{g} / \mathrm{mL}$. Stability indicating assay method was developed and validated as per the ICH guidelines using various parameters, for example, accuracy, precision, limit of quantification, limit of detection, robustness, ruggedness, solution stability, recovery, forced degradation (hydrolysis, photo degradation, thermal degradation, and oxidation), and so forth. Percent relative standard deviation associated with all the parameters was less than 2 , showing compliance with the acceptance criteria of ICH guidelines. The developed method was very sensitive as limit of quantification and limit of detection were found to be $0.025 \mu \mathrm{g} / \mathrm{mL}$ and $0.00625 \mu \mathrm{g} / \mathrm{mL}$, respectively. Forced degradation studies of drug reveal good stability under the chosen experimental conditions.
\end{abstract}

\section{Introduction}

Chemically, the Frovatriptan Succinate Monohydrate (FSM) is 3-methylamino-6-carboxamido-1,2,3,4-tetrahydrocarbazole succinate monohydrate (Figure 1). It is a potent and selective agonist of $5-\mathrm{HT}_{1 \mathrm{~B}}$ and $5-\mathrm{HT}_{1 \mathrm{D}}$ receptors. By acting on $5-\mathrm{HT}_{1 \mathrm{~B}}$ receptor, it causes constriction of dilated arteriovenous anastomoses. The action on $5-\mathrm{HT}_{1 \mathrm{D}}$ causes the inhibition of Substance $P$ and calcitonin gene-related peptide (CGRP) release. Among all the triptans, it has the longest elimination half-life $\left(t_{1 / 2}\right)$ of 26 hours. This carabzole derivative was approved by FDA in 2001. It has all the ideal characteristics to be used as a first line drug for menstruation migraine [1-3].

Despite tremendous utility of FSM in migraine, there was no simple, sensitive, and reliable stability indicating that UV spectroscopic method has been reported for its analysis in the vast reviewed literature. Only two UV spectroscopic methods have been mentioned in the literature for the analysis of FSM in $0.1 \mathrm{~N} \mathrm{NaOH}$ and $0.1 \mathrm{~N} \mathrm{HCl}$ at $280.2 \mathrm{~nm}$ and $279 \mathrm{~nm}$, but these methods are less sensitive and tedious to be used for routine purposes because they involve first-order derivatization, second-order derivatization, and area-under the-curve (AUC) analysis in order to make their method sensitive $[4,5]$. HPLC methods were reported in the literature for their analysis in dosage forms and in blood samples [68]. Till now, no forced degradation data is available in the literature for FSM.

As in pharmaceutical industry, time and expense play a very crucial role. Pharmaceutical industries always admire simple and more sensitive methods for routine usage. Therefore, a need of simple, reliable, inexpensive, and accurate stability indicating method for analysis of FSM as bulk or as pharmaceutical dosage forms has always been felt.

The present study was aimed to develop and validate analytical methods for the analysis of FSM in distilled water, phosphate buffer ( $\mathrm{pH}$ 6.7), and acetate buffer ( $\mathrm{pH}$ 5.5) at two different storage conditions, that is, room temperature 


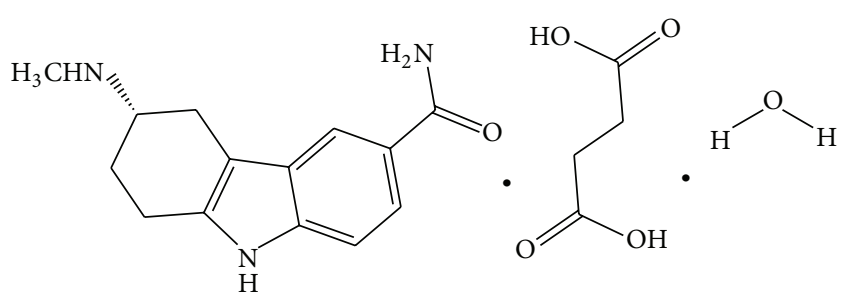

Figure 1: Structure of Frovatriptan Succinate Monohydrate (FSM).

$\left(25^{\circ} \mathrm{C}\right)$ and freeze temperature $\left(5^{\circ} \mathrm{C}\right)$ at $244 \mathrm{~nm}$. Forced degradation studies were carried out using aqueous solution of FSM $(2.5 \mu \mathrm{g} / \mathrm{mL})$. Test solution was exposed to various types of ICH prescribed stress conditions, like hydrolysis (neutral, acid catalyzed, and base catalysed), photolysis, thermal degradation, and oxidation, so as to check its stability. Developed methods were validated as per ICH guidelines and validation data was evaluated with the aid of various statistical parameters [9].

\section{Materials and Methods}

2.1. Chemicals and Reagents. FSM was procured as a gift sample from Azakem Labs Pvt. Ltd., India. Potassium dihydrogen orthophosphate, sodium hydroxide, and sodium acetate trihydrate were obtained from Himedia Ltd., India. Hydrogen peroxide $(30 \% \mathrm{w} / \mathrm{v})$ was obtained from Moly chem., India. All other chemicals used were of analytical grade.

2.2. Instruments. Double beam UV-visible spectrophotometer (Shimadzu, UV-1800, Japan) in connection with computer having UV Probe 2.34 software and equipped with matched quartz cells of $1.0 \mathrm{~cm}$ each was used.

2.3. Construction of Calibration Plot. Different stock solutions were prepared in distilled water, phosphate buffer $(\mathrm{pH}$ 6.7), and acetate buffer ( $\mathrm{pH}$ 5.5) by accurately weighing about $156.4 \mathrm{mg}$ of FSM (equivalent to $100 \mathrm{mg}$ of frovatriptan) in a volumetric flask of $100 \mathrm{~mL}$ capacity. Volume was made up to the mark using suitable media. Different dilutions were made in the range of $1 \mu \mathrm{g} / \mathrm{mL}-3.5 \mu \mathrm{g} / \mathrm{mL}$ and analysed.

\subsection{Analytical Method Validation}

2.4.1. Accuracy. Accuracy of the developed method was determined with the aid of three different concentration levels, namely, low concentration (LC) $2.0 \mu \mathrm{g} / \mathrm{mL}$, intermediate concentration (IC) $2.5 \mu \mathrm{g} / \mathrm{mL}$, and a higher concentration (HC) $3.0 \mu \mathrm{g} / \mathrm{mL}$. LC, IC, and HC were prepared in all the three media from independent stock solutions, in duplicate, and were analysed $(n=3)$. Accuracy of the method was determined with the help of standard deviation (SD), percent relative standard deviation (RSD), and recovery at each level.

2.4.2. Precision. Repeatability and intermediate precision studies were determined for developed methods using same concentration levels as were taken in accuracy studies. Percent RSD and recovery were taken as precision measure.
2.4.3. Linearity. Linearity was determined by preparing a series of dilutions in three media and then measuring the absorbance at $244 \mathrm{~nm}(n=3)$, so as to find out the range over which Beer's law followed. Linear regression coefficient value $\left(R^{2}\right)$ was taken as linearity measure.

2.4.4. Limit of Quantification (LOQ) and Limit of Detection (LOD). LOD and LOQ measurements were determined by subjecting minimum concentration of calibration plot to series of dilutions. Absorbance was measured in replicate of six for each case, till RSD (\%) was came as $\geq 10 \%$ and $\geq 30 \%$, which signify LOQ and LOD of the developed method.

2.4.5. Robustness. Robustness was determined by taking similar concentration levels as were taken in accuracy studies and storing them at two different temperatures $\left(5^{\circ} \mathrm{C}\right.$ and $25^{\circ} \mathrm{C}$ ) and by varying the $\mathrm{pH}$ of the media by \pm 0.1 units.

2.4.6. Forced Degradation Studies. Test solution $(2.5 \mu \mathrm{g} / \mathrm{mL})$ was exposed to different strengths of hydrochloric acid $(0.1 \mathrm{~N}$ to $1.0 \mathrm{~N})$, sodium hydroxide $(0.1 \mathrm{~N}$ to $1.0 \mathrm{~N})$, and hydrogen peroxide solutions (from $3 \% \mathrm{w} / \mathrm{v}$ to $30 \% \mathrm{w} / \mathrm{v}$ ), and the extent of degradation was analysed with respect to time and volume of exposure. Test solution was also exposed separately to the radiations of $300-800 \mathrm{~nm}$ and to $70^{\circ} \mathrm{C}$ temperature to evaluate the extent of photolytic and thermal degradation, respectively $[10,11]$.

\section{Results}

3.1. Calibration Curve. Least square regression equation of FSM in different media at two different temperatures had shown $R^{2}$ value close to 1 which ensured high degree of positive correlation between the two variables, namely, absorbance and concentration.

\subsection{Analytical Method Validation}

3.2.1. Accuracy. Accuracy data associated with LC, IC, and $\mathrm{HC}$ is mentioned in Table 1 . In each case, RSD (\%) was less than 2, which shows compliance with $\mathrm{ICH}$ guidelines. Recovery as in accuracy studies were found to be 100\%-104\% for distilled water, $97 \%-100 \%$ for phosphate buffer ( $\mathrm{pH} 6.7$ ), and $96 \%-100 \%$ for acetate buffer ( $\mathrm{pH} 5.5$ ), respectively.

3.2.2. Precision. The RSD (\%) data associated with repeatability studies ranges from 0.432 to 1.139 and 0.332 to 1.392 for distilled water at freeze temperature and room temperature, respectively. The \% RSD data associated with repeatability studies in phosphate buffer ( $\mathrm{pH}$ 6.7) ranges from $0.460-1.283$ and $0.666-1.119$ at freeze temperature and room temperature, respectively. The \% RSD data associated with repeatability studies in acetate buffer $(\mathrm{pH} 5.5)$ ranges from 0.706 to 1.722 and 0.275 to 1.004 at freeze temperature and room temperature, respectively. In intermediate precision, values of RSD (\%) varies from 0.563 to 1.254 and 0.578 to 1.164 for distilled water at freeze temperature and room temperature, respectively. The phosphate buffer $(\mathrm{pH}$ 6.7) values of RSD 
TABLE 1: Accuracy data of developed method for analysis of FSM in various media $(n=3)$.

\begin{tabular}{|c|c|c|c|c|c|c|c|}
\hline \multirow{3}{*}{ Media } & \multirow{3}{*}{ Levels } & \multicolumn{6}{|c|}{ Storage conditions } \\
\hline & & \multicolumn{3}{|c|}{ Freeze $\left(5^{\circ} \mathrm{C} \pm 0.5^{\circ} \mathrm{C}\right)$} & \multicolumn{3}{|c|}{$\operatorname{Room}\left(25^{\circ} \mathrm{C} \pm 0.5^{\circ} \mathrm{C}\right)$} \\
\hline & & Absorbance $( \pm \mathrm{SD})$ & RSD (\%) & Recovery (\%) & Absorbance $( \pm \mathrm{SD})$ & RSD (\%) & Recovery (\%) \\
\hline \multirow{3}{*}{ Distilled water } & LC & $0.351 \pm 0.001$ & 0.285 & 103.931 & $0.352 \pm 0.003$ & 0.714 & 104.320 \\
\hline & IC & $0.441 \pm 0.003$ & 0.600 & 104.112 & $0.437 \pm 0.004$ & 0.804 & 103.102 \\
\hline & $\mathrm{HC}$ & $0.514 \pm 0.003$ & 0.625 & 100.997 & $0.520 \pm 0.003$ & 0.484 & 102.161 \\
\hline \multirow{3}{*}{ Phosphate buffer (pH 6.7) } & LC & $0.388 \pm 0.002$ & 0.536 & 100.139 & $0.382 \pm 0.004$ & 0.944 & 97.460 \\
\hline & IC & $0.475 \pm 0.004$ & 0.740 & 98.154 & $0.475 \pm 0.004$ & 0.740 & 97.580 \\
\hline & $\mathrm{HC}$ & $0.578 \pm 0.003$ & 0.556 & 99.849 & $0.578 \pm 0.003$ & 0.612 & 97.425 \\
\hline \multirow{3}{*}{ Acetate buffer ( $\mathrm{pH}$ 5.5) } & LC & $0.374 \pm 0.003$ & 0.706 & 98.289 & $0.364 \pm 0.001$ & 0.275 & 96.313 \\
\hline & IC & $0.480 \pm 0.006$ & 1.163 & 99.404 & $0.471 \pm 0.004$ & 0.925 & 99.756 \\
\hline & $\mathrm{HC}$ & $0.554 \pm 0.007$ & 1.212 & 98.275 & $0.567 \pm 0.006$ & 1.003 & 100.047 \\
\hline
\end{tabular}

TABLE 2: Linearity data for developed method of FSM.

\begin{tabular}{lccccc}
\hline \multirow{2}{*}{ Media } & \multicolumn{2}{c}{ Storage conditions } & \multicolumn{2}{c}{ Room $\left(25^{\circ} \mathrm{C} \pm 0.5^{\circ} \mathrm{C}\right)$} \\
& Slope & Freeze $\left(5^{\circ} \mathrm{C} \pm 0.5^{\circ} \mathrm{C}\right)$ & \multicolumn{2}{c}{ Slope } & Intercept \\
\hline Distilled water & 0.1716 & -0.0058 & 0.9984 & 0.1716 & -0.0058 \\
Phosphate buffer (pH 6.7) & 0.1889 & +0.0138 & 0.9983 & 0.1885 & +0.0009 \\
Acetate buffer (pH 5.5) & 0.1914 & +0.005 & 0.9999 & 0.1901 & 0.9995 \\
\hline
\end{tabular}

TABLE 3: LOQ and LOD data for developed method of FSM $(n=6)$.

\begin{tabular}{lcc}
\hline Concentration $(\mu \mathrm{g} / \mathrm{mL})$ & Absorbance $( \pm \mathrm{SD})$ & RSD $(\%)$ \\
\hline 0.025 & $0.028 \pm 0.003$ & 11.208 \\
0.0125 & $0.013 \pm 0.003$ & 27.200 \\
0.006 & $0.009 \pm 0.003$ & 30.051 \\
\hline
\end{tabular}

(\%) vary from 1.020 to 1.397 and 1.089 to 1.371 at freeze temperature and room temperature, respectively. The acetate buffer ( $\mathrm{pH} 5.5$ ) values of RSD (\%) vary from 0.629 to 1.344 and 0.684 to 1.100 at freeze temperature and room temperature, respectively. Recovery ranges from $96 \%$ to $104.9 \%$ in both types of precision study.

3.2.3. Linearity. Beer's law follows over the range of $1.0 \mu \mathrm{g} / \mathrm{mL}-4.5 \mu \mathrm{g} / \mathrm{mL}$ in all the media at both storage conditions. The values of slope, intercept, and regression coefficient $\left(R^{2}\right)$ associated with linearity plots are listed in Table 2. Values of regression coefficients are close to 1 which shows that there is a directed positive correlation between the two variables, namely, absorbance and concentration (Figure 2).

3.2.4. $L O Q$ and $L O D$. LOQ and LOD for FSM were found to be $0.025 \mu \mathrm{g} / \mathrm{mL}$ and $0.00625 \mu \mathrm{g} / \mathrm{mL}$, respectively. Data associated with LOD and LOQ analysis is mentioned in Table 3.

3.2.5. Robustness. Variation in $\mathrm{pH}$ of media by \pm 0.1 unit and storage conditions do not seem to have effect on the absorption values and $\lambda_{\max }$ (Table 4 ).
TABLE 4: Effect of change in $\mathrm{pH}$ of media by \pm 0.1 unit on the sensitivity of developed method of FSM $(n=6)$.

\begin{tabular}{lcc}
\hline Concentration $(\mu \mathrm{g} / \mathrm{mL})$ & Absorbance $( \pm \mathrm{SD})$ & RSD $(\%)$ \\
\hline 2 & $0.346 \pm 0.001$ & 0.371 \\
2.5 & $0.436 \pm 0.002$ & 0.479 \\
3 & $0.520 \pm 0.003$ & 0.289 \\
\hline
\end{tabular}

When paired Student's $t$-test (two tailed) was applied on the accessed data, calculated value (0.9073) was much less than that of the table value at $95 \%$ confidence level, which ensures the robustness of the experiment. Similar results were obtained when prepared dilutions were subjected to two different storage conditions (freeze and room) for 24 hours.

3.2.6. Forced Degradation Studies. Test solution was found to undergo photolysis after 12 hours of exposure to radiations ranging from 300 to $800 \mathrm{~nm}$. Extent of degradation after 12 hours was found to be $31.34 \%$. Plot constructed between amount remaining to degrade ( $y$-axis) and time ( $x$-axis) yields a straight line curve with a negative slope $R^{2}$ value of 0.9421 (Table 5).

Storage of test solution at $70^{\circ} \mathrm{C}$ for 7 days yields no significant degradation (Table 6).

When constant volume $(1.0 \mathrm{~mL})$ of various strengths $\mathrm{HCl}$ from $(0.1 \mathrm{~N}$ to $1.0 \mathrm{~N})$ was added individually to $10 \mathrm{~mL}$ of test solution, it was found to be stable in $0.1 \mathrm{~N}, 0.2 \mathrm{~N}, 0.3 \mathrm{~N}$, and $0.4 \mathrm{~N} \mathrm{HCl}$ for 6 hours without heating. Addition of other strengths of $\mathrm{HCl}$ yields significant degradation of more than $31 \%$ within 6 hours of exposure (Table 7 and Figure 3). 


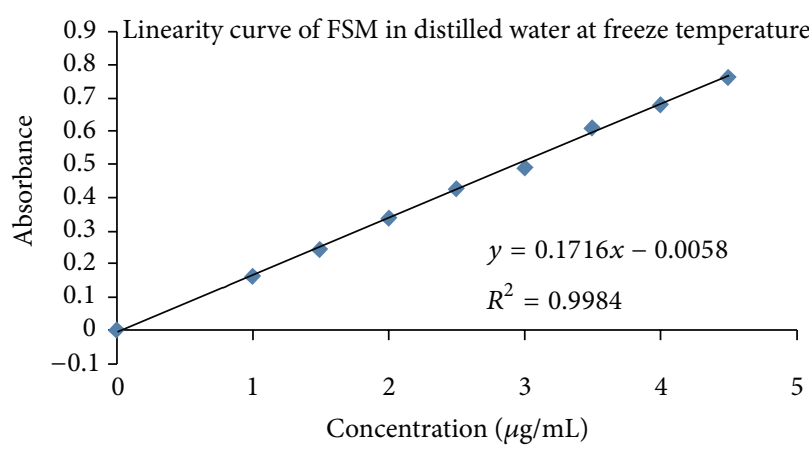

(a)

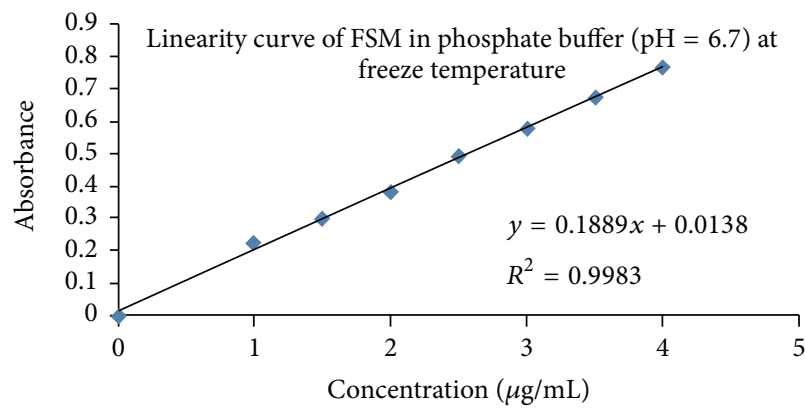

(c)

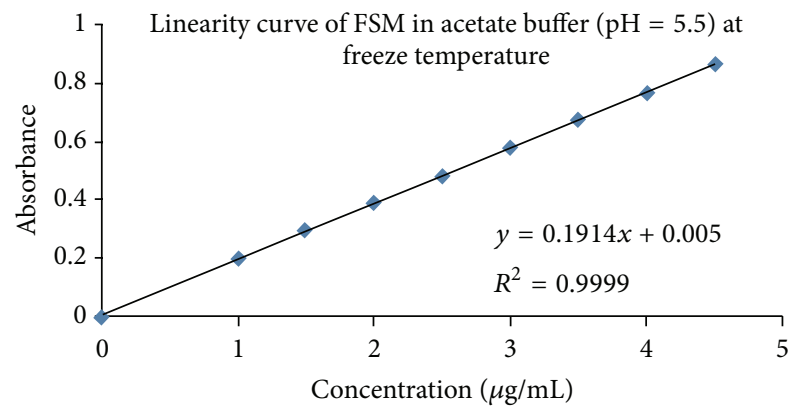

(e)

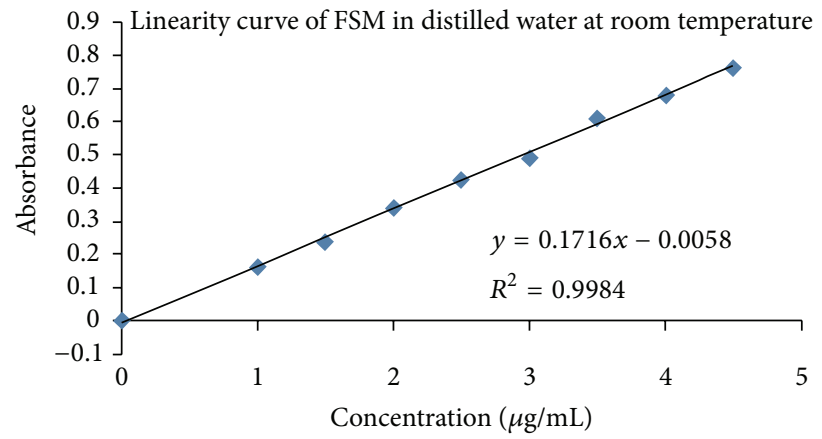

(b)

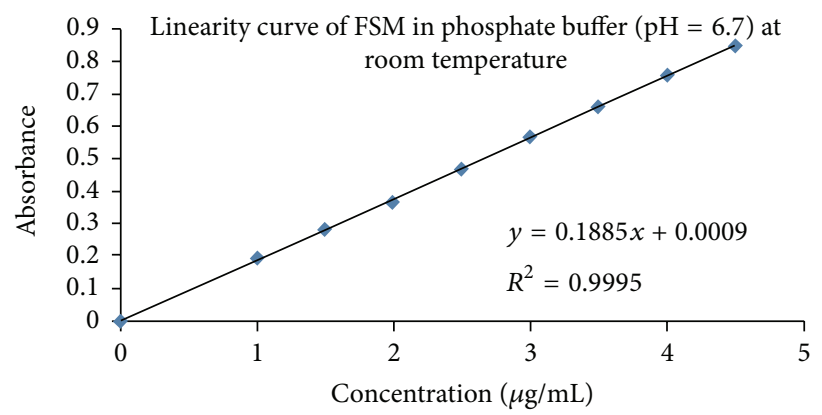

(d)

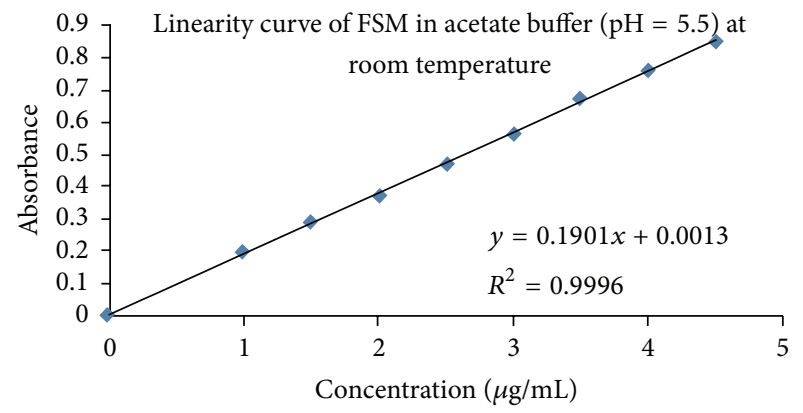

(f)

FIGURE 2: Linearity plots of FSM in different media. (a) Linearity curve of FSM in distilled water at freeze temperature, (b) linearity curve of FSM in distilled water at room temperature, $(\mathrm{c})$ linearity curve of FSM in phosphate buffer $(\mathrm{pH}=6.7)$ at freeze temperature, $(\mathrm{d})$ linearity curve of FSM in phosphate buffer $(\mathrm{pH}=6.7)$ at room temperature, $(\mathrm{e})$ linearity curve of FSM in acetate buffer $(\mathrm{pH}=5.5)$ at freeze temperature, and (f) linearity curve of FSM in acetate buffer $(\mathrm{pH}=5.5)$ at freeze temperature.

TABLE 5: Photolytic degradation of FSM $(n=6)$.

\begin{tabular}{lccc}
\hline $\begin{array}{l}\text { Time } \\
\text { (hours })\end{array}$ & $\begin{array}{c}\text { Concentration remaining } \\
(\mu \mathrm{g} / \mathrm{mL} \pm \mathrm{SD})\end{array}$ & RSD (\%) & Degradation (\%) \\
\hline 0 & $2.415 \pm 0.003$ & 0.554 & 3.532 \\
0.5 & $2.391 \pm 0.002$ & 0.338 & 4.498 \\
1 & $2.393 \pm 0.001$ & 0.220 & 4.424 \\
2 & $2.390 \pm 0.000$ & 0.000 & 4.572 \\
3 & $2.219 \pm 0.001$ & 0.136 & 11.636 \\
6 & $2.160 \pm 0.003$ & 0.697 & 14.089 \\
9 & $2.060 \pm 0.002$ & 0.396 & 18.253 \\
12 & $1.744 \pm 0.001$ & 0.126 & 31.338 \\
\hline
\end{tabular}

TABLE 6: Thermal stability data of FSM $(n=6)$.

\begin{tabular}{lcc}
\hline Time (days) & $\begin{array}{c}\text { Concentration remaining } \\
(\mu \mathrm{g} / \mathrm{mL} \pm \mathrm{SD})\end{array}$ & RSD $(\%)$ \\
\hline 1 & $2.498 \pm 0.002$ & 0.449 \\
2 & $2.493 \pm 0.002$ & 0.330 \\
3 & $2.489 \pm 0.002$ & 0.331 \\
4 & $2.485 \pm 0.001$ & 0.217 \\
5 & $2.489 \pm 0.002$ & 0.331 \\
6 & $2.493 \pm 0.002$ & 0.330 \\
7 & $2.489 \pm 0.001$ & 0.125 \\
\hline
\end{tabular}


TABLE 7: Acid catalysed hydrolysis of FSM $(n=6)$.

\begin{tabular}{lccc}
\hline & \multicolumn{3}{c}{ Amount remaining to degrade $(\mu \mathrm{g} / \mathrm{mL})$} \\
Strength $(\mathrm{N})$ & \multicolumn{3}{c}{ Time $(t)$ (hours) } \\
& 0 & 3 & 6 \\
\hline 0.1 & 2.437 & 2.437 & 2.383 \\
0.2 & 2.344 & 2.153 & 2.114 \\
0.3 & 2.129 & 2.011 & 2.015 \\
0.4 & 2.108 & 1.966 & 1.959 \\
0.5 & 1.957 & 1.645 & 1.613 \\
0.6 & 1.862 & 1.568 & 1.508 \\
0.7 & 1.839 & 1.469 & 1.428 \\
0.8 & 1.791 & 1.378 & 1.325 \\
0.9 & 1.563 & 1.282 & 1.114 \\
1 & 1.417 & 1.271 & 0.817 \\
\hline
\end{tabular}

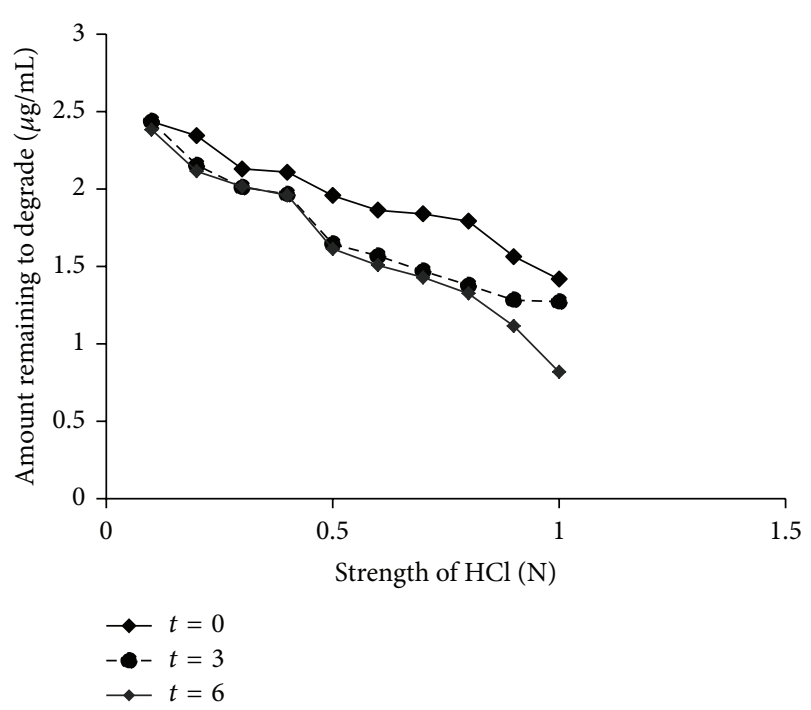

FIGURE 3: Forced degradation (acid catalysed hydrolysis) plots of FSM.

Exposure of test solution to various strength of $\mathrm{NaOH}$ from $(0.1 \mathrm{~N}$ to $1.0 \mathrm{~N})$ without heating over 6 hours showed its stability in $0.1 \mathrm{~N}$ only (Table 8 and Figure 4 ). In the rest of the sample solutions, significant degradation occurs within 6 hours of exposure (>30\%).

In oxidative degradation studies, FSM was found to be stable on the exposure of $\leq 0.2 \mathrm{~mL}$ volume of $3 \% \mathrm{w} / \mathrm{v}$ solution of hydrogen peroxide per $10 \mathrm{~mL}$ of test solution without heating. Addition of more volume $(>0.2 \mathrm{~mL})$ or solution containing higher concentration of hydrogen peroxide causes immediate degradation of test samples (Table 9 and Figure 5).

Test solution was found to be stable for 90 days on storage at room temperature $\left(25^{\circ} \mathrm{C} \pm 0.5^{\circ} \mathrm{C}\right)$.

\section{Discussion}

Different media for analytical method development were selected based on the solubility of drug, economy, and applicability of the developed method. Values of $R^{2}$ in calibration
TABLE 8: Base catalysed hydrolysis of FSM $(n=6)$.

\begin{tabular}{|c|c|c|c|}
\hline \multirow{3}{*}{ Strength (N) } & \multicolumn{3}{|c|}{ Amount remaining to degrade $(\mu \mathrm{g} / \mathrm{mL})$} \\
\hline & \multicolumn{3}{|c|}{ Time $(t)$ (hours) } \\
\hline & 0 & 3 & 6 \\
\hline 0.1 & 2.486 & 2.461 & 2.451 \\
\hline 0.2 & 1.727 & 1.693 & 1.535 \\
\hline 0.3 & 1.697 & 1.669 & 1.472 \\
\hline 0.4 & 1.644 & 1.588 & 1.423 \\
\hline 0.5 & 1.558 & 1.549 & 1.388 \\
\hline 0.6 & 1.443 & 1.434 & 1.362 \\
\hline 0.7 & 1.414 & 1.389 & 1.346 \\
\hline 0.8 & 1.347 & 1.339 & 1.294 \\
\hline 0.9 & 1.283 & 1.240 & 1.160 \\
\hline 1 & 1.153 & 1.056 & 0.955 \\
\hline
\end{tabular}

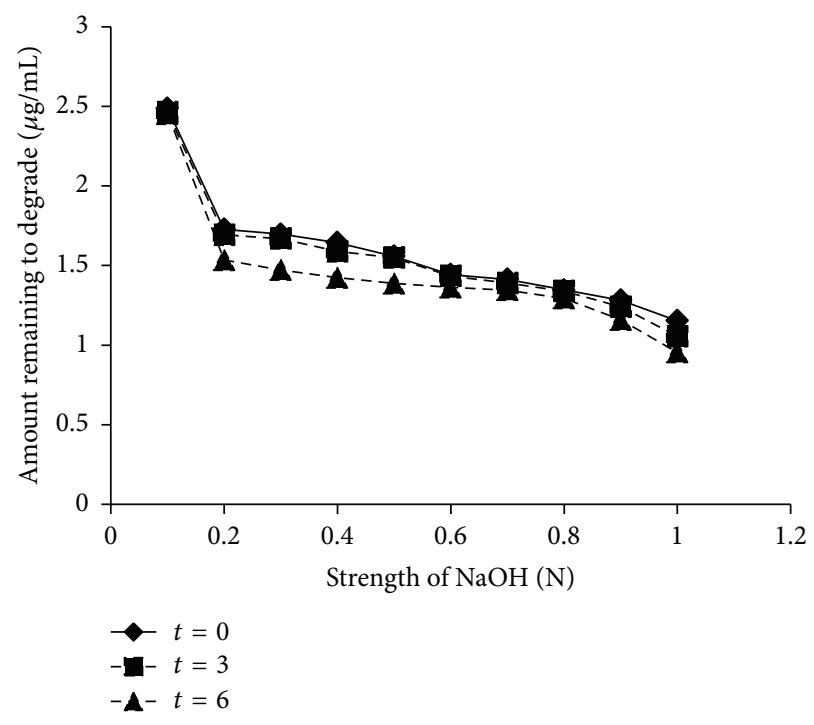

FIGURE 4: Forced degradation (base catalysed hydrolysis) plots of FSM.

plots and during linearity analysis were near to 1 in each case, which show direct positive correlation between the concentration of the solution and the absorption of UV light. Analyses of accuracy and precision data show that the method is accurate and reliable. LOD and LOQ data analysis reflect that the developed method is very sensitive and selective. Forced degradation studies were performed as per ICH guidelines, and it was found that FSM was stable in these stressed conditions.

\section{Conclusion}

FSM is a potent and selective agonist of $5-\mathrm{HT}_{1 \mathrm{~B}}$ and $5-\mathrm{HT}_{1 \mathrm{D}}$ receptors. Among all the triptans, it has the longest elimination half-life of 26 hours, even after 11 years of its existence in pharmaceutical market, till now no simple, sensitive, and economical UV-spectroscopy method for the analysis of FSM has been reported. Hence, an attempt had been taken to the developed method in distilled water, phosphate buffer $(\mathrm{pH}$ 
TABLE 9: Oxidative stability data of FSM.

\begin{tabular}{|c|c|c|c|c|c|c|}
\hline \multirow{3}{*}{$\begin{array}{l}\text { Time } \\
\text { (minutes) }\end{array}$} & \multicolumn{6}{|c|}{ Volume of $3 \% \mathrm{w} / \mathrm{v}$ solution added per $10 \mathrm{~mL}$ of drug solution } \\
\hline & $0.1 \mathrm{~mL}$ & $0.15 \mathrm{~mL}$ & $0.2 \mathrm{~mL}$ & $0.1 \mathrm{~mL}$ & $0.15 \mathrm{~mL}$ & $0.2 \mathrm{~mL}$ \\
\hline & Concentration $(\mu \mathrm{g} / \mathrm{mL})$ & Concentration $(\mu \mathrm{g} / \mathrm{mL})$ & Concentration $(\mu \mathrm{g} / \mathrm{mL})$ & Degradation (\%) & Degradation (\%) & Degradation (\%) \\
\hline 0 & 2.390 & 2.390 & 2.390 & 4.385 & 4.385 & 4.385 \\
\hline 15 & 2.389 & 2.381 & 2.381 & 4.456 & 4.743 & 4.743 \\
\hline 90 & 2.381 & 2.376 & 2.372 & 4.743 & 4.959 & 5.102 \\
\hline 180 & 2.372 & 2.358 & 2.358 & 5.102 & 5.676 & 5.676 \\
\hline 360 & 2.360 & 2.331 & 2.329 & 5.605 & 6.753 & 6.825 \\
\hline
\end{tabular}

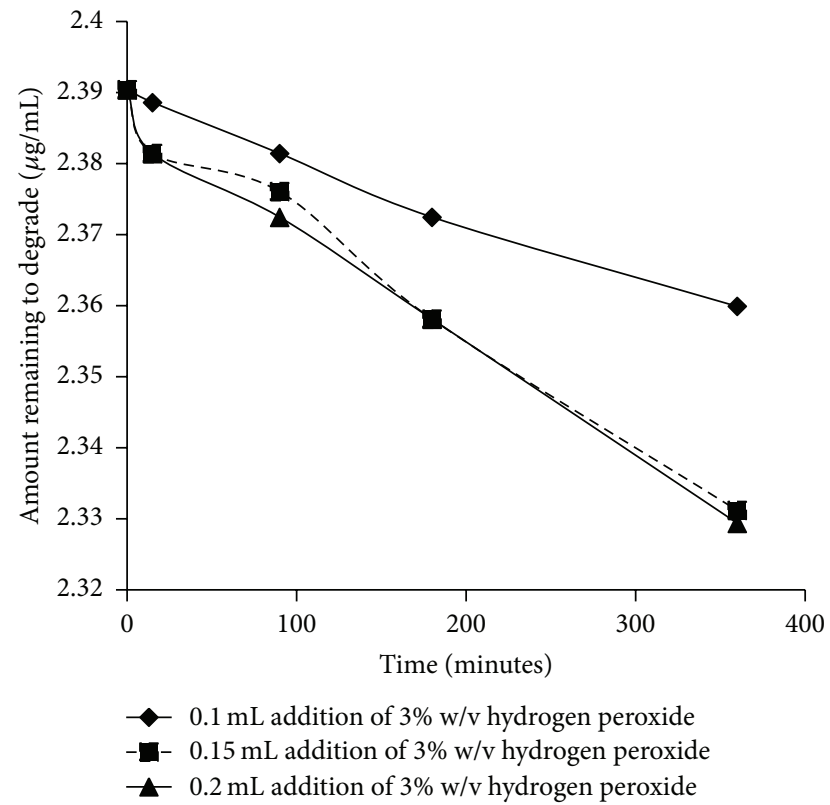

FIGURE 5: Oxidative degradation plots of FSM using hydrogen peroxide as oxidizing agent.

6.7), and acetate buffer ( $\mathrm{pH}$ 5.5). The developed method was found to be reliable and accurate. Irrespective to media, FSM shows the maximum absorbance at the wavelength of $244 \mathrm{~nm}$. Forced degradation studies show stability of FSM test solution under the chosen experimental conditions.

\section{References}

[1] L. Kelman, "Review of frovatriptan in the treatment of migraine," Journal of Neuropsychiatric Disease and Treatment, vol. 4, no. 1, pp. 49-54, 2008.

[2] E. A. Balbisi, "Frovatriptan: a review of pharmacology, pharmacokinetics and clinical potential in the treatment of menstrual migraine," Journal of Therapeutics and Clinical Risk Management, vol. 2, no. 3, pp. 303-308, 2006.

[3] P. T. Hansen, "Frovatriptan for acute treatment of migraine," European Journal of Neurology, vol. 6, no. 4, pp. 262-264, 2011.

[4] S. K. Acharjya, P. Mallick, P. Panda, and M. M. Annapurna, "Spectrophotometric methods for the determination of Frovatriptan succinate monohydrate in bulk and Pharmaceutical dosage forms," International Journal of Pharmacy and Technology, vol. 2, no. 3, pp. 565-576, 2010.

[5] S. K. Acharjya, P. Panda, P. Mallick, and M. M. Annapurna, "Validated spectrophotometric methods for determination of Frovatriptan Succinate Monohydrate in pharmaceutical dosage forms," Der Pharmacia Lettre, vol. 2, no. 4, pp. 452-460, 2010.

[6] N. U. Rani, R. S. Rao, K. Saraswathi, and T. E. G. K. Murthy, "RP-HPLC and spectrophotometry method for the analysis of frovatriptan in formulations," International Journal of Science Innovations and Discoveries, vol. 1, no. 1, pp. 53-61, 2011.

[7] S. G. Kumara, J. M. R. Kumar, J. V. L. N. S. Rao, and D. V. Kumar, "Development and validation of RP-HPLC method for the estimation of frovatriptan succinate in bulk and tablet dosage form," Journal of Pharmacy Research, vol. 52, no. 2, pp. 894-895, 2012.

[8] L. Laugher, R. Briggs, J. Doughty, and T. A. G. Noctor, "Development of an analytical methodology from toxicokinetic to clinical studies for the anti-migraine drug frovatriptan," Chromatographia, vol. 52, pp. S113-S119, 2000.

[9] S. Boltan and C. Bon, Pharmaceutical Statistics Practical and Clinical Applications, Informa Healthcare, New York, NY, USA, 5th edition, 2010.

[10] A. F. Aubry, P. Tattersall, and J. Ruan, "Development of stability indicating methods," in Handbook of Stability Testing in Pharmaceutical Development Regulation, Methodologies and Best Practice, H. B. Kim, Ed., pp. 146-149, Springer, New York, NY, USA, 1st edition, 2009.

[11] P. C. Meier and E. R. Zünd, Statistical Methods in Analytical Chemistry, John Wiley \& Sons, Toronto, Canada, 2nd edition, 2000. 

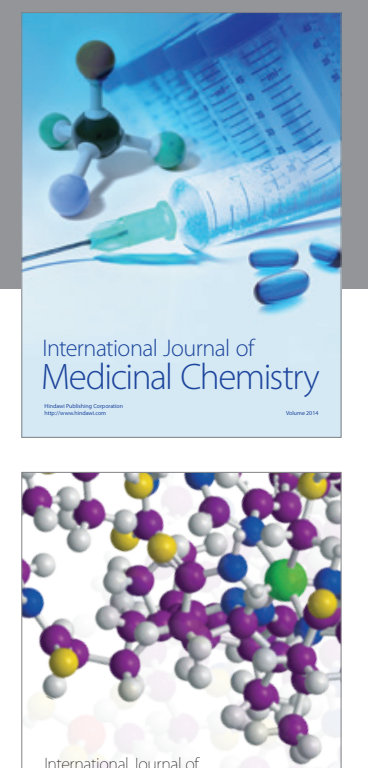

\section{Carbohydrate} Chemistry

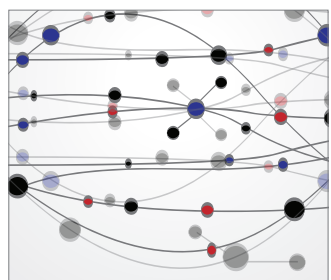

The Scientific World Journal
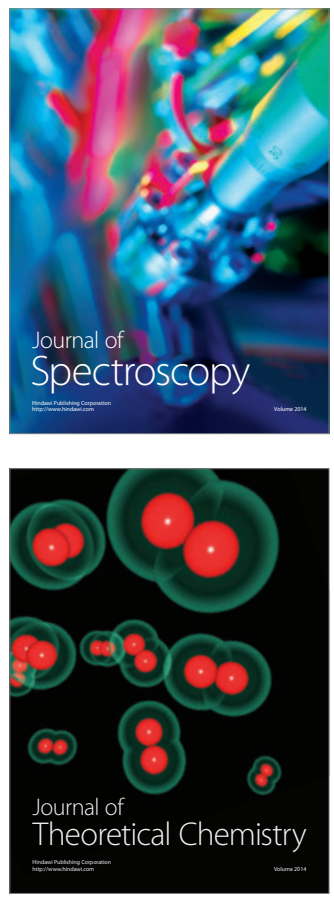
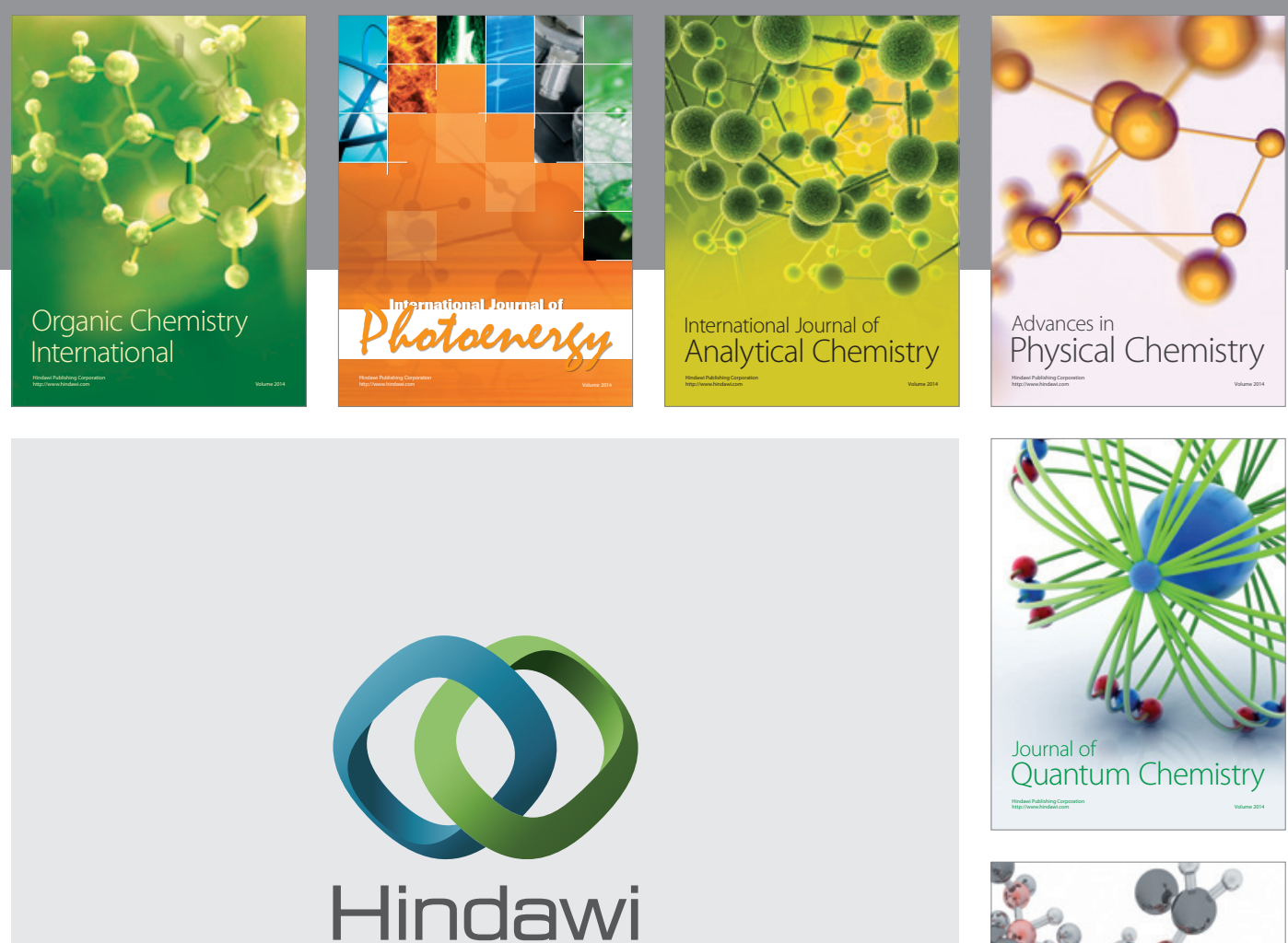

Submit your manuscripts at

http://www.hindawi.com

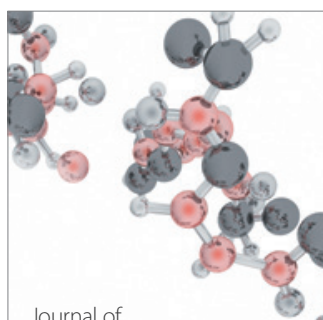

Analytical Methods

in Chemistry

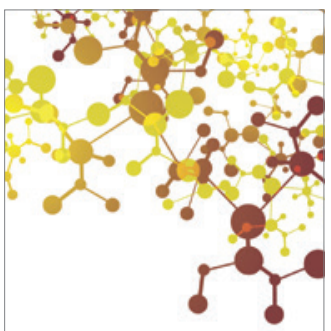

Journal of

Applied Chemistry

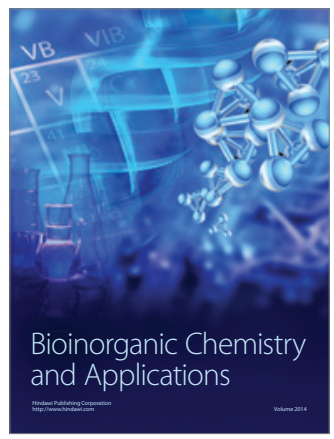

Inorganic Chemistry
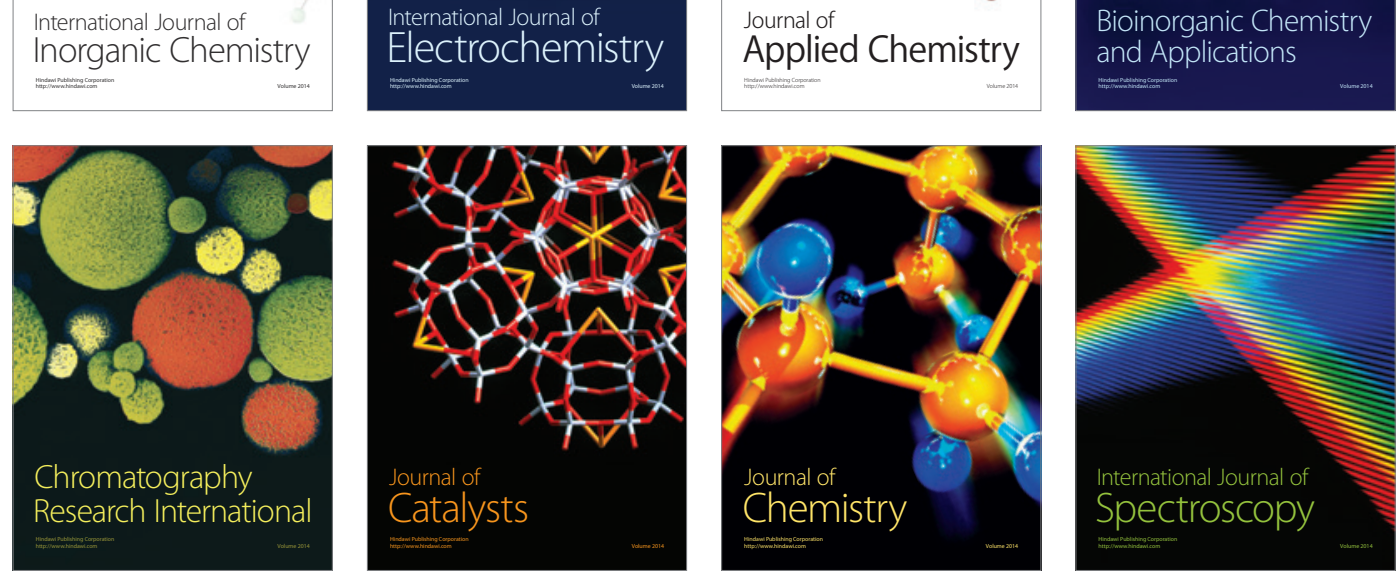